\title{
Periodic Flow Purging System for Harvesting Fibers from Screens
}

Aerosol and Air Quality Research

\author{
Bon Ki Ku${ }^{1 *}$, Gregory Deye ${ }^{1}$, Leonid A. Turkevich ${ }^{2}$ \\ ${ }^{1}$ Health Effects Laboratory Division (HELD), National Institute for Occupational Safety and Health \\ (NIOSH), Centers for Disease Control and Prevention (CDC), Cincinnati, Ohio 45226, USA \\ 2 Division of Field Studies \& Engineering (DFSE), National Institute for Occupational Safety and \\ Health (NIOSH), Centers for Disease Control and Prevention (CDC), Cincinnati, Ohio 45226, USA
}

Fiber length is believed to be an important factor in determining various toxicological responses to asbestos and other bio-persistent fibers. Length classification of fibers thus is crucial for toxicological assessment. Nylon mesh screens have been shown to be effective in separating fibers by length. In this note, we report development of a purging flow system for harvesting fibers from a nylon net screen, with the aim of separating airborne fibers by length. We evaluated the performance of this purging flow system by examining the lengths of glass fibers collected on a screen. Fibers aerosolized by vortex shaking were provided to $10 \mu \mathrm{m}$ and $20 \mu \mathrm{m}$ mesh screens, and the fibers collected on each screen were purged periodically with a backflow. The length of the purged fibers was measured and compared to that of fibers washed from the screen. The mean length of fibers on the screen is larger than that of the fibers in the original test aerosol. The mean length of the backflow purged fibers is smaller than that of the fibers from the washed screen. The results indicate that the purging flow system with screens can harvest the longer fibers from the original aerosol.

Keywords: Glass fiber, Fiber length, Nylon mesh screens, Length separation, Purging system

\section{OPEN ACCESS}

Received: February 12, 2021

Revised: March 23, 2021

Accepted: March 25, 2021

\section{${ }^{*}$ Corresponding Author: \\ bku@cdc.gov}

\section{Publisher:}

Taiwan Association for Aerosol Research

ISSN: $1680-8584$ print

ISSN: 2071-1409 online

(c) Copyright: U.S. Government work. This is an open access article distributed under the terms of the Creative Commons Attribution License (CC BY 4.0), which permits unrestricted use, distribution, and reproduction in any medium, provided the original author and source are cited.

\section{INTRODUCTION}

Inhaled airborne asbestos fibers are implicated in a variety of respiratory diseases, such as mesothelioma and lung cancer (Kamp, 2009; NIOSH, 2011). Classification of airborne fibers by length is essential for sample preparation in any experiment that seeks to understand the effect of fiber length on toxicity (Stanton and Layard, 1978; Stanton et al., 1981; Davis et al., 1986; Donaldson et al., 1989; Goodglick and Kane 1990; Blake et al., 1998; Miller et al., 1999; Baron, 2001; Dodson et al., 2003; Zeidler-Erdely et al., 2006; Donaldson et al., 2010; NIOSH, 2011; Schinwald et al., 2012; Padmore et al., 2017). Toxicology sample preparation also requires length separation in significantly higher quantities than is required in typical analytical methods.

Previous studies showed that fibers penetrating through screens were predominantly short fibers and that, depending on screen pore sizes and configurations, long fibers could be completely excluded from the transmitted aerosol (Spurny et al., 1969; Myojo, 1999; Ku et al., 2014). Ku et al. (2014) demonstrated that nylon mesh screens can be effective in obtaining short fibers which penetrate through the screens. Conversely, long fibers could be harvested from the screen surfaces (Ku et al., 2017a). Ku et al. (2017b) have extended these studies to mesh screens of various pore sizes.

However, if fibers are allowed to accumulate on the mesh screen, they will form deposits, and the retained fibers alter the screen selection characteristics (depth filtration effect). Kasper et al. (2009) confirmed this effect of particle loading on collection efficiency with spherical challenge particles. To minimize the loading effect on screen collection efficiency, and to harvest the long fibers collected on the screen, a method for recovering the collected fibers from the screen is 
required. Ku et al. (2017a) recently reported that fibers could be harvested from the screen by back-flow purging.

This note reports on the development and evaluation of a periodic flow purging system of a screen for use in length separation of airborne fibers. The periodic purging reduces fiber accumulation on the screen, thereby minimizing the depth filtration change in screen performance. We have also harvested long fibers collected on the screen and compared the length distributions of the harvested fibers to those of fibers obtained from washing the screen.

\section{EXPERIMENTAL}

As a surrogate for asbestos, we have used the same glass fibers (supplied by the Japan Fibrous Material Research Association (JFMRA)-Kohyama et al., 1997), as in our previous studies (Ku et al., 2013, 2014, 2017a, b, 2018).

Fig. 1 is a schematic diagram of the periodic flow purging system and a flow diagram for screen collection of fibers and their subsequent recovery from the screen.

The periodic flow purging system consists of a vortex shaker, flow control valves and switches, and screen mesh system. Aerosolized fibers are generated by vortex shaking of the fiber powder (Ku et al., 2014). Initially, fibers are aerosolized from the bulk powder at RH $30-50 \%$ : saturated air is supplied at near-ambient temperature and at 15 psi gauge pressure; sub-saturation $\mathrm{RH}$ $\sim 50 \%$ results from a reduction to atmospheric pressure. This elevated humidity prevents fiber charging and promotes aerosolization from the vortex shaker (Baron et al., 1994; Deye et al., 1999; Ku et al., 2013). The generation proceeds for $30 \mathrm{sec}$ at $1.5 \mathrm{~L} \mathrm{~min}^{-1}$ (open switches R1, R3, R5). The vortex shaker is switched off for $10 \mathrm{sec}$, and then the flow is reversed through the screen for $30 \mathrm{sec}$ (open switches R2, R4); the 'desorbed' fibers are collected on the sampler (located after R4) at $4.5 \mathrm{~L} \mathrm{~min}^{-1}$. During this collection phase, a second humidifier, at close to ambient temperature, provides $80 \% \mathrm{RH}$ air that more effectively removes the glass fibers from the nylon screen (the use of dry air for fiber desorption is ineffective-see below). The shorter duty cycle maintains the temperature of the second humidifier.

The flow and fiber generation are computer controlled (LabView software, National Instruments, Austin, TX). The flows are controlled by relay operated valves (USB miniLAB 1008 DIO data acquisition interface, Measurement Computing, Norton, MA), designed to cyclically open and close valves (12 V DC Honeywell Skinner Valves).

\subsection{Fiber Length Analysis}

Fibers are collected on a $0.8 \mu \mathrm{m}$ pore size mixed cellulose ester (MCE) filter ( $25 \mathrm{~mm}$ in diameter, SKC Inc., Eighty Four, PA); the fiber-loaded MCE filter is rendered transparent using hot acetone vapor before fiber images are taken (Ku et al., 2014, 2018) by a (PCM) phase contrast microscope (Motic Instruments, Inc., British Columbia, Canada). Typically, 200-300 fibers are imaged and measured; the length data is then statistically analyzed to obtain cumulative length distributions.

Distributions for penetrating fibers (sampled at R3), backflushed fibers (sampled at R4) and challenge fibers (sampled upstream), were compared. For each screen, two independent runs were performed (Table S1). Kolmogorov-Smirnov statistical analysis was used to determine any difference between penetrating, backflushed and total fiber samples. Details of the statistical analysis are provided in the Supplemental Material.

\subsection{Screen Washing Procedure}

In place of backflushing, we have also studied the fibers collected on the screen by washing the screen. The screen is removed from the pathway and separated from its holder. Because of the hydrophilic nature of glass fibers and nylon, water is used to wash the screens. The $25 \mathrm{~mm}$ screen is placed on the inside of a $50 \mathrm{~mL}$ test tube and is submerged in $20 \mathrm{~mL}$ of deionized water. The tube is capped and agitated with a vortex shaker for 20 seconds. The liquid slurry is decanted into a $20 \mathrm{~mL}$ glass vacuum filtration assembly with a $0.8 \mu \mathrm{m}$ MCE filter. This procedure is repeatedthus, a total of $40 \mathrm{~mL}$ of wash is filtered through the same MCE filter. The filter is transferred to a glass slide with the fiber collection side downward against the top surface of the slide. The filter is dried by placing a porous stainless-steel filter support pad on the wet filter and placing 


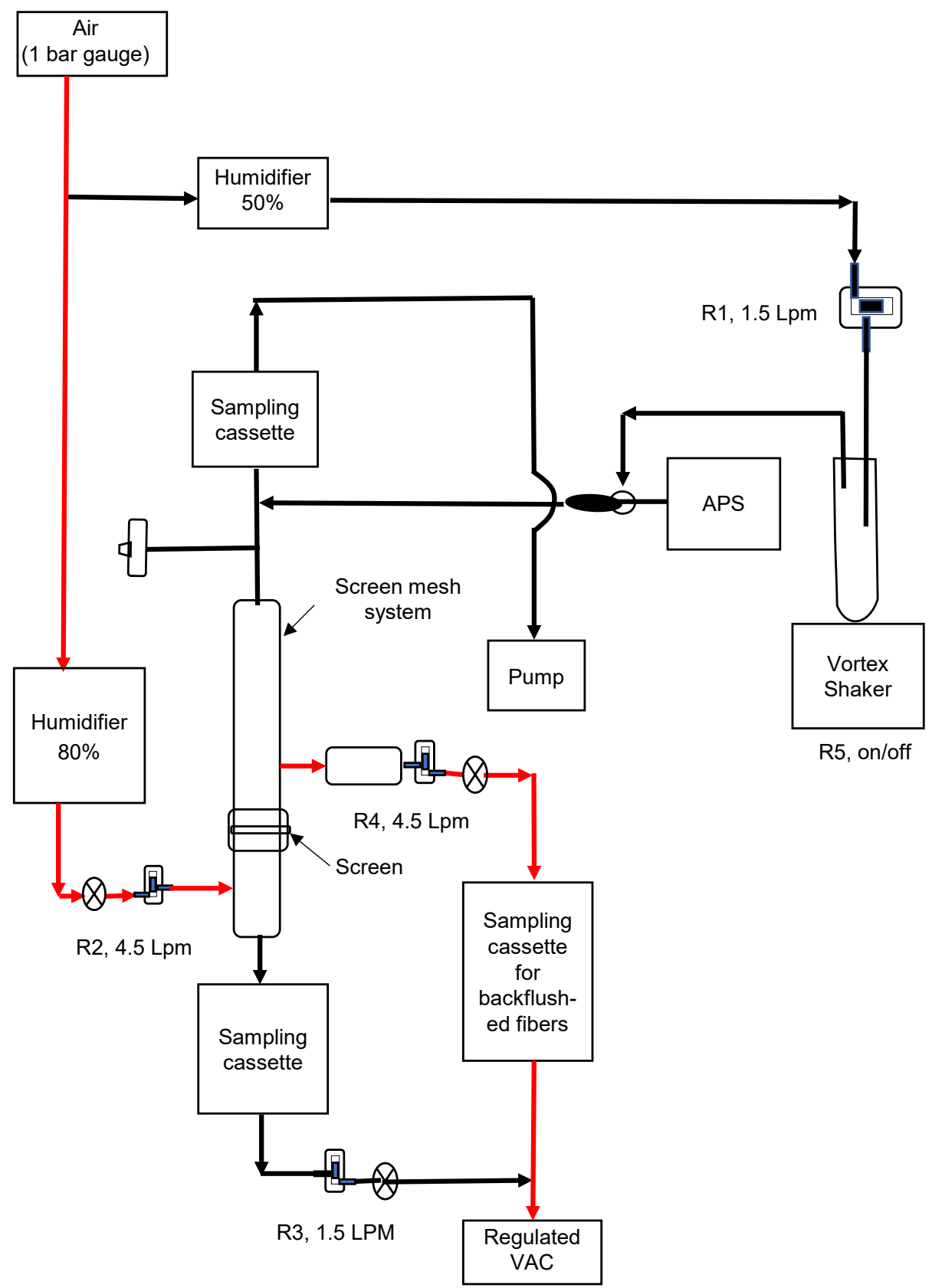

Fig. 1. Schematic diagram for generating and sampling fibers with a periodic flow purging system. The backflushing flow lines are marked in red. APS: Aerodynamic particle sizer.

the slide on a heater plate at $120^{\circ} \mathrm{C}$ for 5 minutes. After cooling, this filter is rendered transparent with acetone (Ku et al., 2014).

\section{RESULTS AND DISCUSSION}

Fig. 2 shows the fiber length distributions from one experiment with a $10 \mu \mathrm{m}$ screen: i) the incoming aerosol stream (open squares); ii) the penetrating aerosol (closed triangles); iii), the backflush aerosol (closed squares); iv) residue from filtering the washed screen (closed circles).

The length of penetrating fibers $\left(L_{50 \%}=6.5 \mu \mathrm{m}\right)$ is clearly shorter than the length of the original aerosol fibers $\left(L_{50 \%}=15 \mu \mathrm{m}\right)$, consistent with the results from Ku et al. (2014). The length of the backflush purged fibers $\left(L_{50 \%}=22 \mu \mathrm{m}\right)$ and of the fibers from the wash of the screens $\left(L_{50 \%}=32 \mu \mathrm{m}\right)$ are both longer than that of the original fibers. The length of the fibers in the wash residue 


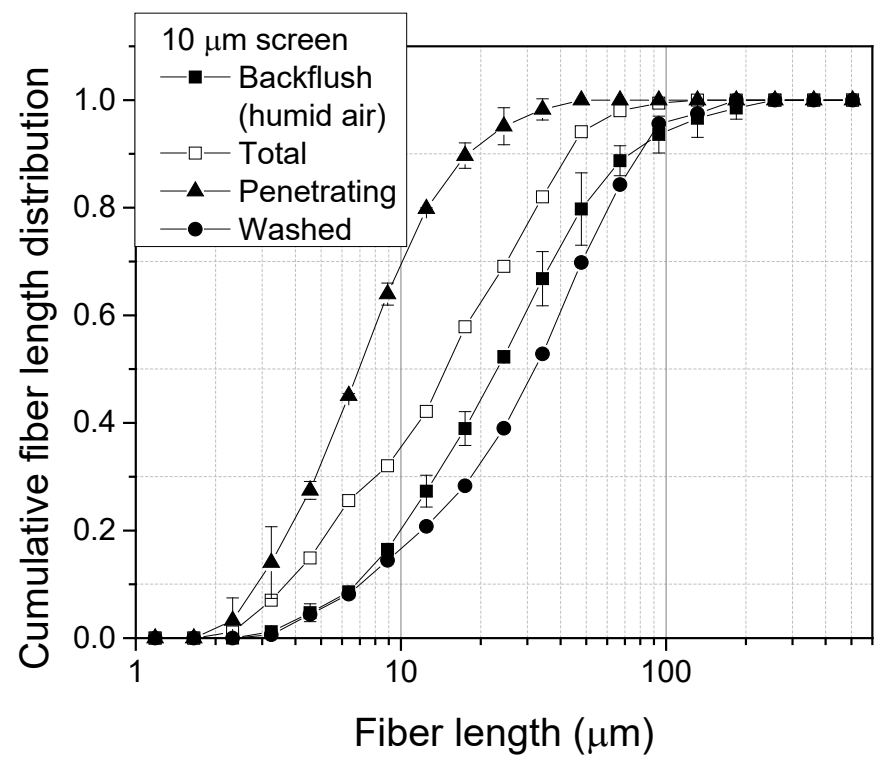

Fig. 2. Cumulative fiber length distributions of fibers using a $10 \mu \mathrm{m}$ screen: 'backflush' fibers are obtained by flow purging the screen; 'total' is the incoming aerosol; 'penetrating' fibers are transmitted through the screen; 'washed' fibers are obtained from washing the screen off-line. Error bars indicate one standard deviation.

is longer than that of the backflow purged fibers, indicating that the backflush does not remove the longest fibers that adhere to the screen.

We used the two sample Kolmogorov-Smirnov statistical test to quantify the differences in the cumulative fiber-length distributions; details are provided in the Supplemental Material. Additional statistical measures of these fiber length distributions are summarized in Table S1 of the Supplemental Material.

It is important to evaluate the fraction of fibers longer than $20 \mu \mathrm{m}$; this critical length is relevant as a typical size of a human macrophage and is also the size above which fiber-challenged alveolar macrophages exhibit enhanced cytokine response (Padmore et al., 2017). Ideally, we wish to separate short and long fibers into distinct, non-overlapping populations, with $20 \mu \mathrm{m}$ as the cutoff length. Only $6-10 \%$ of the penetrating fibers have lengths exceeding $20 \mu \mathrm{m}$; thus, the short fibers can be separated with only $10 \%$ contamination (by long fibers). Similarly, $55-59 \%$ of the backflushed, and $68-73 \%$ of the washed, fibers have lengths exceeding $20 \mu \mathrm{m}$; thus, the long fibers can be separated with $30-40 \%$ contamination (by short fibers).

We have repeated these experiments with screens of different mesh sizes. Fig. 3 shows the length distributions obtained when a $20 \mu \mathrm{m}$ screen is used. The length distributions are similar to those obtained (Fig. 2) when a $10 \mu \mathrm{m}$ screen is used: the lengths associated with the $50 \%$ cumulative fraction of the length distribution from the different fiber populations are $\mathrm{L}_{50 \%}=6.3 \mu \mathrm{m}$ (penetrating fibers), $18 \mu \mathrm{m}$ (original aerosol) $26 \mu \mathrm{m}$ (backflush aerosol), and $39 \mathrm{~mm}$ (washed fibers).

Fig. 3 also shows a difference when dry and humid air is used for the backflush. Purging with dry air was performed without the second humidifier. Utilizing dry air generates a backflush aerosol (closed squares) indistinguishable from the original test aerosol (open circles). It is only when humid air is used (open squares) that the backflush desorbs the longer fibers that adhere to the screen. Optical microscope images taken of the screen confirm that the screen purged with humid air is relatively clean, as compared to the screen purged with dry air.

Fig. 4 compares the fiber length distributions of the wash residues (closed symbols) for experiments conducted with $10 \mu \mathrm{m}, 20 \mu \mathrm{m}, 30 \mu \mathrm{m}$ and $41 \mu \mathrm{m}$ screens. The length distribution of the fibers washed from the screens depends only weakly on the screen mesh size; this is not understood.

Further study is necessary to determine the screen collection and desorption of fibers with different physicochemical properties (e.g., hydrophobic or hydrophilic surfaces). 


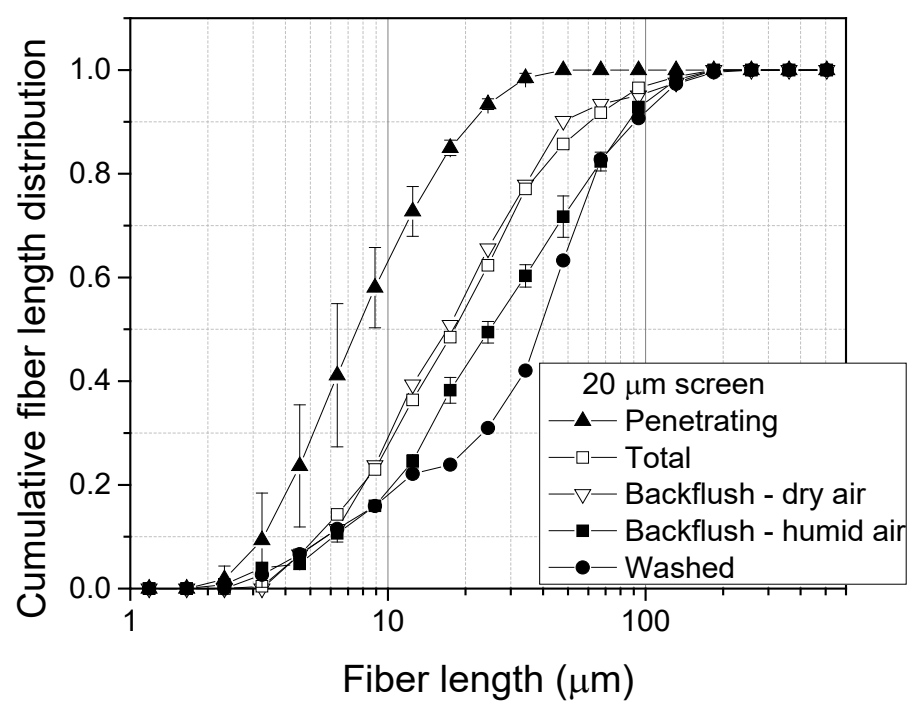

Fig. 3. Cumulative fiber length distributions of fibers using a $20 \mu \mathrm{m}$ screen: 'total' is the incoming aerosol stream (open circle), penetrating aerosol (open triangle), backflush using dry air (closed square), backflush using humid air (open square). Error bars indicate one standard deviation.

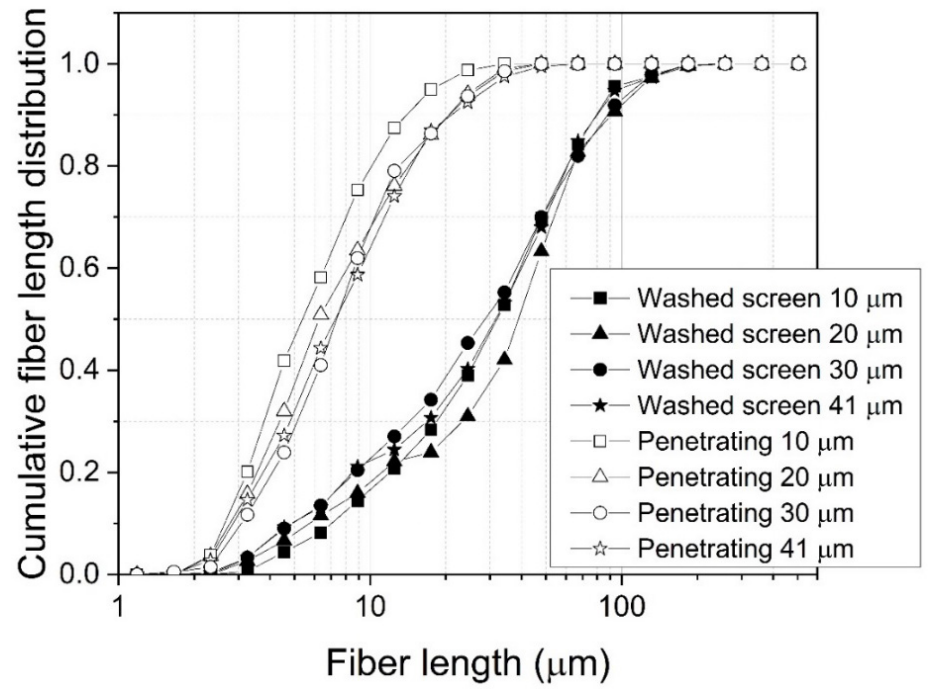

Fig. 4. Comparison of fiber length distributions for the $10 \mu \mathrm{m}$ (squares) and $20 \mu \mathrm{m}$ (triangles) screen experiments: penetrating aerosol (open symbols), wash residue (closed symbols). For comparison, the fibers recovered from washing $30 \mu \mathrm{m}$ and $41 \mu \mathrm{m}$ screens, are included.

\section{CONCLUSIONS}

We have developed and evaluated a periodic screen flow purging system as a method to obtain long fibers from an aerosol. The flow purging system minimizes fiber overloading on the screen, thereby enabling prolonged use. The backflush purging with humid air can detach the longer fibers that adhere to the screen although the backflush process does not remove the longest, most strongly adhering fibers from the screen. As shown previously, the aerosol that penetrates the screen primarily contains the shorter fibers.

\section{ACKNOWLEDGMENTS}

The authors thank Pramod Kulkarni, Ronnee Andrews and Paul Siegal (NIOSH/HELD) for their 
helpful comments on this work, and Peter Shaw (NIOSH/HELD) for discussion on statistical analysis. We thank Mariko Ono-Ogasawara (Japan NIOSH) for the samples of the glass fibers. The National Institute for Occupational Safety and Health funded this work under the CAN 9277066.

\section{DISCLAIMER}

The mention of any company or product does not constitute an endorsement by the National Institute for Occupational Safety and Health, Centers for Disease Control and Prevention. The findings and conclusions in this paper are those of the authors and do not necessarily represent the views of the National Institute for Occupational Safety and Health, Centers for Disease Control and Prevention.

\section{SUPPLEMENTARY MATERIAL}

Supplementary data associated with this article can be found in the online version at https://doi.org/10.4209/aaqr.210033

\section{REFERENCES}

Baron, P.A., Deye, G.J., Fernback, J. (1994). Length separation of fibers. Aerosol Sci. Technol. 21, 179-192. https://doi.org/10.1080/02786829408959707

Baron, P.A. (2001). Measurement of airborne fibers: A review. Ind. Health 39, 39-50. https://doi.org/10.2486/indhealth.39.39

Blake, T., Castranova, V., Schwegler-Berry, D., Baron, P., Deye, G.J., Li, C., Jones, W. (1998). Effect of fiber length on glass microfiber cytotoxicity. J. Toxicol. Environ. Health A 54, 243-259. http://dx.doi.org/10.1080/009841098158836

Davis, J.M.G., Addison, J., Bolton, R.E., Donaldson, K., Jones, A.D., Smith, T. (1986). The pathogenicity of long versus short fibre samples of amosite asbestos administered to rats by inhalation and intraperitoneal injection. Br. J. Exp. Pathol. 67, 415-430.

Deye, G.J., Gao, P., Baron, P.A., Fernback, J.E. (1999). Performance evaluation of a fiber length classifier. Aerosol Sci. Technol. 30, 420-437. https://doi.org/10.1080/027868299304471

Dodson, R.F., Atkinson, M.A., Levin, J.L. (2003). Asbestos fiber length as related to potential pathogenicity: A critical review. Am. J. Ind. Med. 44, 291-297. https://doi.org/10.1002/ajim.10 263

Donaldson, K., Brown, G.M., Brown, D.M., Bolton, R.E., Davis, J.M. (1989). Inflammation generating potential of long and short fibre amosite asbestos samples. Br. J. Ind. Med. 46, 271276. https://www.jstor.org/stable/27726775

Donaldson, K., Murphy, F.A., Duffin, R., Poland, C.A. (2010). Asbestos, carbon nanotubes and the pleural mesothelium: A review of the hypothesis regarding the role of long fibre retention in the parietal pleura, inflammation and mesothelioma. Part. Fibre Toxicol. 7, 5. https://doi.org/ 10.1186/1743-8977-7-5

Goodglick, L.A., Kane, A.B. (1990). Cytotoxicity of long and short crocidolite asbestos fibers in vitro and in vivo. Cancer Res. 50, 5153-5163.

Kamp, D.W. (2009). Asbestos-induced lung diseases: An update. Transl. Res. 153, 143-152. https://doi.org/10.1016/j.trsl.2009.01.004

Kasper, G., Schollmeier, S., Meyer, J., Hoferer, J. (2009). The collection efficiency of a particleloaded single filter fiber. J. Aerosol Sci. 40, 993-1009. https://doi.org/10.1016/j.jaerosci.2009. 09.005

Kohyama, N., Tanaka, I., Tomita, M., Kudo, M., Shinohara, Y. (1997). Preparation and characteristics of standard reference samples of fibrous minerals for biological experiments. Ind. Health 35 , 415-432. https://doi.org/10.2486/indhealth.35.415

Ku, B.K., Deye, G., Turkevich, L.A. (2013). Characterization of a vortex shaking method for aerosolizing fibers. Aerosol Sci Technol 47, 1293-301. https://doi.org/10.1080/02786826.2013. 836588 
Ku, B.K., Deye, G.J., Turkevich, L.A. (2014). Efficacy of screens in removing long fibers from an aerosol stream - sample preparation technique for toxicology studies. Inhalation Toxicol. 26, 70-83. https://doi.org/10.3109/08958378.2013.854851

Ku, B.K, Deye, G., Turkevich, L.A. (2017a). Screen collection and harvesting of airborne glass fibers. The abstract of 2017 AAAR Conference, Oct. 16-20, Raleigh, NC.

Ku, B.K., Deye, G., Turkevich, L.A. (2017b). Screen collection efficiency of airborne fibers with monodisperse length. J. Aerosol Sci. 114, 250-262. https://doi.org/10.1016/j.jaerosci.2017.09. 006

Ku, B.K., Deye, G., Turkevich, L.A. (2018). Direct measurement of aerosol glass fiber alignment in a DC electric field. Aerosol Sci. Technol. 52, 123-135. https://doi.org/10.1080/02786826.2017. 1387640

Miller, B.G., Searl, A., Davis, J.M.G., Donaldson, K., Cullen, R.T., Bolton, R.E., Buchanan, D., Soutar, C.A. (1999). Influence of fibre length, dissolution and biopersistence on the production of mesothelioma in the rat peritoneal cavity. Ann. Occup. Hyg. 43, 155-166. https://doi.org/10.1 093/annhyg/43.3.155

Myojo, T. (1999). A simple method to determine the length distribution of fibrous aerosols. Aerosol Sci. Technol., 30, 30-39. https://doi.org/10.1080/027868299304868

National Institute for Occupational Safety and Health (NIOSH) (2011). Asbestos fibers and other elongate mineral particles: State of the science and roadmap for research [DHHS (NIOSH) Publication No. 2011-159]. http://www.cdc.gov/niosh/docs/2011-159/pdfs/2011-159.pdf

Padmore, T., Stark, C., Turkevich, L.A., Champion, J.A. (2017). Quantitative analysis of the role of fiber length on phagocytosis and inflammatory response by alveolar macrophages. Biochim. Biophys. Acta 1861, 58-67. https://doi.org/10.1016/j.bbagen.2016.09.031

Schinwald, A., Murphy, F.A., Prina-Mello, A., Poland, C.A., Byrne, F., Movia, D., Glass, J.R., Dickerson, J.C., Schulz, D.A., Jeffree, C.E., MacNee, W., Donaldson, K. (2012). The threshold length for fiber-induced acute pleural inflammation: Shedding light on the early events in asbestosinduced mesothelioma. Toxicol. Sci. 128, 461-470. https://doi.org/10.1093/toxsci/kfs171

Spurny, K.R., Lodge, J.P., Frank, E.R., Sheesley, D.C. (1969). Aerosol filtration by means of Nuclepore filters. Environ. Sci. Technol. 3, 453-464. https://doi.org/10.1021/es60028a005

Stanton, M.F., Layard, M., Tegeris, A., Miller, E., May, M., Morgan, E., Smith, A. (1981). Relation of particle dimension to carcinogenicity in amphibole asbestoses and other fibrous minerals. J. Natl. Cancer Inst. 67, 965-975.

Stanton, M.F., Layard, M.W. (1978). Carcinogenicity of natural and man-made fibers. Adv. Clin. Oncol. 1, 181-187.

Zeidler-Erdely, P.C., Calhoun, W.J., Ameredes, B.T., Clark, M.P., Deye, G.J., Baron, P., Jones, W., Blake, T., Castranova, V. (2006). In vitro cytotoxicity of Manville Code 100 glass fibers: Effect of fiber length on human alveolar macrophages. Part. Fibre Toxicol. 3, 5. https://doi.org/10.1186/ 1743-8977-3-5 